\title{
PENGARUH JARAK TANAM PADA SISTEM TANAM JAJAR LEGOWO TERHADAP PERTUMBUHAN, PRODUKTIVITAS DAN PENDAPATAN PETANI PADI SAWAH DI KABUPATEN SRAGEN JAWA TENGAH
}

\author{
Tota Suhendrata \\ Balai Pengkajian Teknologi Pertanian Jawa Tengah \\ Jl. Soekarno - Hatta KM 26 No. 10 Bergas Kabupaten Semarang \\ e-mail: suhendrata@yahoo.co.id
}

\begin{abstract}
One of the efforts to increase the productivity of paddy rice by setting the right spacing. At this time, developing technology engine planting of rice seedlings (rice transplanter) which introducing plant spacing ranging from narrow spacing to large plant spacing both on legowo row planting system and tile planting system. With regard to the introduction of these technologies, further research is needed in the effect of plant spacing on growth, productivity (grain yield) and income of paddy rice farmers. The assessment was carried out on the wetland of farmer group of Rukun Tani Sulur Blimbing Village of Sragen Regency on July - October 2014. The assessment consisted of 3 planting distance treatment of legowo row 2: 1 planting system, ie $20 \times 10 \times 40 \mathrm{~cm}, 20 \times 13 \times 15 \mathrm{~cm}$ and $20 \times 15 \times 40 \mathrm{~cm}$, each treatment repeated 7 times. The area of each treatment is about 0.33 ha. The assessment involves 7 farmers, each farmer carrying out 3 treatment. The seedlings using legowo 2:1planting system of rice transplanter. This rice transplanter has 3 combination of plant distance, that is $20 \times 10 \times 40 \mathrm{~cm}, 20 \times 13 \times 15 \mathrm{~cm}$ and $20 \times 15 \times 40 \mathrm{~cm}$. The data collected includes the number of productive tillers, productivity, input and output of farming. Data analysis to compare between 3 treatment by using paired t test. While the analysis of financial feasibility of paddy farming technology using partial budget analysis. The results of this assessment showed that a legowo row 2:1 planting system with plant distance $20 \times 15 \times 40 \mathrm{~cm}$ resulted in highest productive tillers, productivity and income compared to the legowo 2:1 with a narrower plant distance $20 \times 10 \times 40$ $\mathrm{cm}$ and $20 \times 13 \times 40 \mathrm{~cm}$.
\end{abstract}

Keywords: plant distance, legowo row, paddy, productivity, income

Abstrak: Salah satu upaya untuk meningkatkan produktivitas padi sawah melalui
pengaturan jarak tanam yang tepat. Pada saat ini, berkembang teknologi mesin tanam
bibit padi (rice transplanter) yang mengintroduksikan jarak tanam mulai dari jarak
tanam sempit sampai dengan jarak tanam lebar baik pada sistem tanam jajar legowo
maupun sistem tanam tegel. Berkenaan dengan introduksi teknologi tersebut perlu
dilakukan penelitian lebih dalam pengaruh jarak tanam terhadap pertumbuhan,
produktivitas (hasil gabah) dan pendapatan petani padi sawah. Pengkajian
dilaksanakan pada lahan sawah kelompok tani Rukun Tani Sulur Desa Blimbing Kec.
Sambirejo Kab. Sragen Jawa Tengah pada MT-3 2014 . Pengkajian terdiri dari 3
perlakuan jarak tanam pada sistem tanam jajar legowo $2: 1$, yaitu $20 \times 10 \times 40 \mathrm{~cm}, 20$
x 13 x $15 \mathrm{~cm}$ dan $20 \times 15 \times 40 \mathrm{~cm}$ dengan 7 kali ulangan. Luas masing-masing
perlakuan sekitar 0,33 ha. Pengkajian melibatkan 7 orang petani, setiap petani
melaksanakan 3 perlakuan. Tanam bibit padi menggunakan mesin tanam bibit padi 4
baris sistem tanam jajar legowo $2: 1$. Mesin tanam ini mempunyai 3 kombinasi jarak
tanam, yaitu $20 \times 10 \times 40 \mathrm{~cm}, 20 \times 13$ x $15 \mathrm{~cm}$ dan $20 \times 15 \times 40 \mathrm{~cm}$. Data yang
dikumpulkan meliputi jumlah anakan produktif, produktivitas, input dan output
usahatani. Analisis data untuk membandingkan antara 3 perlakuan jarak tanam 
Tota Suhendrata : Pengaruh Jarak Tanam Pada Sistem Tanam...

dilakukan uji t berpasangan dengan menggunakan software SPSS Statistics 17.0. Sedangkan analisis kelayakan finansial teknologi usahatani padi sawah menggunakan analisis anggaran parsial. Hasil pengkajian menunjukkan bahwa sistem tanam jajar legowo 2:1 dengan jarak tanam lebar $(20 \times 15 \times 40 \mathrm{~cm})$ menghasilkan jumlah anakan produktif, produktivitas dan pendapatan yang lebih tinggi dibandingkan sistem tanam jajar legowo 2:1 dengan jarak tanam yang lebih sempit $(20 \mathrm{x} 10 \mathrm{x} 40 \mathrm{~cm}$ dan $20 \mathrm{x} 13 \mathrm{x}$ $40 \mathrm{~cm})$.

Kata kunci: jarak tanam, jajar legowo, padi sawah, produktivitas, pendapatan

\section{PENDAHULUAN}

Salah satu upaya untuk meningkatkan produktivitas padi melalui perbaikan teknologi budidaya antara lain pengaturan jarak tanam. Jarak tanam dipengaruhi oleh sifat varietas padi yang ditanam dan kesuburan tanah. Menurut Sembiring (2008) keberhasilan peningkatan produksi padi lebih banyak disumbangkan oleh peningkatan produktivitas dibandingkan dengan peningkatan luas panen. Berbeda jarak tanam akan memberikan capaian hasil yang berbeda akibat populasi tanaman yang tidak sama (Abdulrachman et al., 2013). Jarak tanam akan mempengaruhi hasil dengan dua cara, yakni penggunaan jarak tanam yang terlalu rapat, tanaman akan mengalami kompetisi dengan tanaman lain didekatnya. Pemakaian jarak tanam yang terlalu lebar mungkin akan mengurangi hasil per satuan luas, karena jumlah tanamannya menjadi berkurang, meskipun ukuran produksi dari masing-masing individu tanaman makin besar. Kerapatan tanam sangat mempengaruhi pertumbuhan, perkembangan dan hasil padi. Jarak tanam bergantung pada kesuburan tanah, musim, dan varietas yang ditanam (Sumarno dan Harnoto dalam Sulistiani, 2009). Menurut Masdar (2005), jarak tanam berpengaruh terhadap pertumbuhan tanaman karena berhubungan dengan persaingan antar sistem perakaran dalam konteks pemanfaatan pupuk. Kondisi tanah yang subur, menggunakan jarak tanam yang lebih pendek dibandingkan dengan tanah yang kurang subur. Sedangkan menurut Sulistiani (2009) jarak tanam mempengaruhi interaksi hara antara tanaman dan mikroba dalam tanah. Semakin sempit jarak tanam persaingan antara tanaman dan mikroba dalam tanah semakin besar dalam hal pemanfaatan hara. Oleh karena itu pemilihan jarak tanam harus diperhatikan untuk mengoptimalkan pertumbuhan tanaman dan kehidupan mikroba yang kelak akan menentukan kesuburan sawah pada musim berikutnya. Dengan jarak tanam padi yang cukup longgar akan memberi keleluasaan pertumbuhan anakan padi, sinar matahari maksimal diterima semua daun untuk berfotosintesis dan memproduksi gabah.

Sistem tanam jajar legowo merupakan rekayasa sistem tanam dengan mengatur jarak tanam antar rumpun maupun antar barisan sehingga terjadi pemadatan rumpun padi di dalam barisan dan memperlebar jarak antar barisan. Tujuan sistem tanam jajar legowo untuk mendapatkan tambahan populasi per satuan luas dan mendapatkan ruang kosong memanjang sehingga memudahkan dalam pemeliharaan padi. Sistem tanam jajar Legowo 2:1 pada prinsipnya adalah setiap dua baris diselingi satu baris yang kosong dengan lebar dua kali jarak tanam, dan pada jarak tanam dalam baris yang memanjang di perpendek menjadi setengah jarak tanam dalam barisannya. Pada sistem jajar legowo dua baris ini semua rumpun padi berada di barisan pinggir dari pertanaman. Akibatnya semua rumpun padi tersebut memperoleh manfaat dari pengaruh pinggir (Permana, S., 1995).

\section{METODOLOGI}

Pengkajian dilaksanakan pada lahan sawah kelompok tani "Rukun Tani Sulur" Desa Blimbing Kecamatan Sambirejo Kabupaten Sragen Jawa Tengah pada MT-3 2014 atau bulan Juli - Oktober 2014. Pengkajian terdiri dari 3 perlakuan jarak tanam sistem tanam jajar legowo 2:1, yaitu $20 \times 10 \times 40 \mathrm{~cm}, 20 \times 13 \times$ $15 \mathrm{~cm}$ dan $20 \times 15 \times 40 \mathrm{~cm}$, masing-masing perlakuan di ulang 7 kali. Pengkajian melibatkan 7 orang petani, tiap petani melaksanakan 3 perlakuan jarak tanam dan petani dianggap sebagai ulangan. Tanam padi menggunakan mesin tanam bibit padi 4 baris sistem tanam jajar legowo 2:1 (jarwo 
Tota Suhendrata : Pengaruh Jarak Tanam Pada Sistem Tanam...

Tabel 1. Teknologi yang diterapkan pada usahatani padi lahan sawah irigasi di Desa Blimbing Kecamatan Sambirejo Kabupaten Sragen pada MT-3 2014 atau bulan Juli - Oktober 2014

\begin{tabular}{lllll}
\hline & & \multicolumn{3}{c}{ Perlakuan Jarak Tanam } \\
\cline { 2 - 4 } No. & \multicolumn{1}{c}{ Uraian } & \multicolumn{2}{c}{2} & \multicolumn{1}{c}{3} \\
\hline 1 & Benih & Kelas SS & Kelas SS & Kelas SS \\
2 & Varietas & Mekongga & Mekongga & Mekongga \\
3 & Persemaian & Sistem dapog $18 \times 58 \mathrm{~cm}$ & Sistem dapog $18 \times 58 \mathrm{~cm}$ & Sistem dapog $18 \times 58 \mathrm{~cm}$ \\
4 & Penebaran benih & Seeder & Seeder & Seeder \\
5 & Pengolahan lahan & Olah tanah sempurna & Olah tanah sempurna & Olah tanah sempurna \\
6 & Cara tanam & Rice transplanter jarwo & Rice transplanter jarwo & Rice transplanter jarwo \\
7 & Umur bibit & $16-18 \mathrm{hss}$ & $16-18 \mathrm{hss}$ & $16-18 \mathrm{hss}$ \\
8 & Jarak tanam & $20 \times 10 \times 40 \mathrm{~cm}$ & $20 \times 13 \times 40 \mathrm{~cm}$ & $20 \times 15 \times 40 \mathrm{~cm}$ \\
9 & Pupuk: & & & \\
& - Urea & $200 \mathrm{~kg} / \mathrm{ha}$ & $200 \mathrm{~kg} / \mathrm{ha}$ & $200 \mathrm{~kg} / \mathrm{ha}$ \\
& - Phonska & $300 \mathrm{~kg} / \mathrm{ha}$ & $300 \mathrm{~kg} / \mathrm{ha}$ & $300 \mathrm{~kg} / \mathrm{ha}$ \\
10 & Penyemprotan & Sprayer & Sprayer & Sprayer \\
11 & Penyiangan & Gasrok & Gas rok & Gasrok \\
12 & Perontokan padi & Thresher & Thresher & Thresher \\
\hline
\end{tabular}

transplanter atau rice transplanter sistem tanam jajar legowo 2:1). Mesin tanam ini mempunyai 3 kombinasi jarak tanam, yaitu 20 x 10 x $40 \mathrm{~cm}, 20$ x 13 x $15 \mathrm{~cm}$ dan 20 x 15 x 40 $\mathrm{cm}$. Teknologi yang diterapkan pada pengkajian ini disajikan pada Tabel 1 .

Data yang dikumpulkan meliputi jumlah anakan produktif (batang/rumpun), hasil gabah saat panen (gabah kering panen $=$ GKP) dan input dan output usahatani. Data hasil panen diambil dengan cara ubinan dari setiap petak perlakuan dan gabah hasil ubinan $(\mathrm{kg})$ dikonversi ke gabah kering giling (GKG dengan kadar air 14\%). Untuk mengkonversi gabah hasil ubinan digunakan rumus: hasil gabah per hektar $(\mathrm{t} / \mathrm{ha}$ GKG) $=$ hasil ubinan $x$ $\{(100-\mathrm{ka}) / 86\} \times(10 / \mathrm{LU})$, dimana $\mathrm{ka}=\mathrm{kadar}$ air gabah waktu panen; LU = Luas Ubinan $\left(\mathrm{m}^{2}\right)$. Sedangkan data input dan output dari 7 orang petani pelaksana.

Analisis data untuk membandingkan antara 3 perlakuan jarak tanam pada sistem tanam jajar legowo 2:1 dilakukan uji $\mathrm{t}$ berpasangan dengan menggunakan software SPSS Statistics 17.0. Sedangkan analisis kelayakan finansial teknologi usahatani padi sawah menggunakan analisis anggaran parsial (Swastika, 2004) dengan rumus $\mathrm{B} / \mathrm{C}=$ (Pendapatan-Biaya)/ Biaya=
Keuntungan/Biaya, dimana $: \mathrm{B}=$ Benefit atau keuntungan, $\mathrm{C}=$ Cost atau biaya, dan Pendapatan $=$ Hasil panen (gabah kering panen) $\mathrm{x}$ harga gabah.

Tabel 2. Rata-rata jumlah anakan produktif varietas Mekongga umur menjelang panen di Desa Blimbing Kecamatan Sambirejo Kabupaten Sragen pada MT-3 2014

\begin{tabular}{lcc}
\hline Perlakuan & $\begin{array}{c}\text { Jumlah Anakan } \\
\text { Produktif (batang/ } \\
\text { rumpun) }\end{array}$ & $\begin{array}{c}\text { Jumlah Anakan } \\
\text { Produktif } \\
\text { (batang/rumpun) } \\
\text { Deskripsii }\end{array}$ \\
\hline $\begin{array}{l}\text { Jarak tanam } \\
20 \times 10 \times 40 \\
\text { cm }\end{array}$ & $16,9 \mathrm{a}$ \\
$\begin{array}{l}\text { Jarak tanam } \\
20 \times 13 \times 40 \\
\text { cm }\end{array}$ & 17,8 ac \\
Jarak tanam & \\
$20 \times 15 \times 40$ & $\left.13-16^{*}\right)$ \\
cm & \\
\hline Sumber: & \\
\end{tabular}

Sumber: ${ }^{*}$ Suprihatno et al (2011)

Keterangan: Huruf berbeda dibelakang angka menunjukkan berbeda nyata antara perlakuan 
Tota Suhendrata : Pengaruh Jarak Tanam Pada Sistem Tanam...

\section{HASIL DAN PEMBAHASAN}

\section{Jumlah Anakan Produktif}

Menurut Sulistiani (2009) jarak tanam padi yang cukup longgar akan memberi keleluasaan pertumbuhan anakan padi, sinar matahari maksimal diterima semua daun untuk berfotosintesis dan memproduksi gabah. Jumlah anakan produktif merupakan salah satu komponen agronomis yang berpengaruh terhadap hasil panen padi (produktivitas).

Jumlah anakan produktif/rumpun saat menjelang panen tertinggi pada jarak tanam 20 x 15 x $40 \mathrm{~cm}$ dan terendah pada jarak tanam 20 x 10 x $40 \mathrm{~cm}$. Jumlah anakan antar perlakuan jarak tanam menunjukkan ada kecenderungan makin lebar jarak tanam makin besar jumlah anakan produktifnya dan berbeda nyata. Dengan demikian, jarak tanam berpengaruh terhadap jumlah anakan produktif, hal ini menunjukkan bahwa jarak tanam padi yang cukup longgar akan memberi keleluasaan pertumbuhan anakan padi, sinar matahari maksimal diterima semua daun untuk berfotosintesis dan memproduksi gabah. Jumlah anakan produktif pada ketiga jarak tanam lebih besar dari deskripsinya.

Jumlah anakan produktif penerapan paket rice transplanter sistem tanam jajar legowo 2:1 lebih tinggi dan berbeda nyata dibandingkan dengan hasil penerapan paket rice transplanter sistem tanam tegel di Desa Jungke Kecamatan Karanganyar Kabupaten Karanganyar pada MT-3 2014 (Kushartanti dan Suhendrata, 2016).

\section{Produktivitas}

Jarak tanam pada tanaman padi merupakan salah satu faktor penting yang menentukan kualitas dan kuantitas hasil. Berbeda jarak tanam akan memberikan capaian hasil yang berbeda akibat populasi tanaman yang tidak sama (Abdulrachman et al., 2013). Produktivitas hasil ubinan berdasarkan jarak tanam menunjukkan bahwa produktivitas tertinggi dicapai pada jarak tanam $20 \times 15 \times 40$ cm yaitu 9,840 t/ha GKP atau 8,250 t/ha GKG, sedangkan yang terendah pada jarak tanam $20 \mathrm{x}$ $10 \times 40 \mathrm{~cm}$ yaitu $7,906 \mathrm{GKP}$ atau $6,658 \mathrm{t} / \mathrm{ha}$ GKG (Tabel 3). Tabel 3 tersebut menunjukkan bahwa semakin lebar jarak tanam ada kecenderungan hasil gabah semakin tinggi, berbanding terbalik dengan jumlah rumpun per satuan luas (makin lebar jarak tanam, makin sedikit jumlah rumpun per satuan luas). Hasil gabah ini lebih tinggi dibandingkan deskripsinya tetapi masih lebih rendah dibandingkan dengan potensinya.

Tabel 3. Rata-rata hasil gabah varietas Mekongga di Desa Blimbing Kecamatan Sambirejo Kabupaten Sragen pada MT-3 2014 atau bulan Juli - Oktober 2014

\begin{tabular}{|c|c|c|c|c|}
\hline \multirow[b]{2}{*}{ Perlakuan } & \multicolumn{2}{|c|}{$\begin{array}{c}\text { Hasil Gabah } \\
\text { (Produktivitas) }\end{array}$} & \multicolumn{2}{|c|}{ Deskripsi $\left.{ }^{*}\right)$} \\
\hline & t/ha GKP & t/ha GKG & $\begin{array}{c}\text { Hasil (t/ha } \\
\text { GKG) }\end{array}$ & $\begin{array}{c}\text { Hasil (t/ha } \\
\text { GKG) }\end{array}$ \\
\hline $\begin{array}{l}\text { Jarak } \\
\operatorname{tanam} 20 \mathrm{x} \\
10 \times 40 \mathrm{~cm}\end{array}$ & $7,906 \mathrm{a}$ & $6,658 \mathrm{~d}$ & & \\
\hline $\begin{array}{l}\text { Jarak } \\
\text { tanam } 20 \times \\
13 \times 40 \mathrm{~cm}\end{array}$ & $9,064 b$ & $7,636 \mathrm{e}$ & 6,0 & 8,4 \\
\hline $\begin{array}{l}\text { Jarak } \\
\text { tanam } 20 \times \\
15 \times 40 \mathrm{~cm}\end{array}$ & $9,840 \mathrm{~b}$ & $8,250 \mathrm{e}$ & & \\
\hline
\end{tabular}

Sumber : $\quad{ }^{*}$ Suprihatno et al (2011)

Keterangan : Huruf berbeda dibelakang angka menunjukkan berbeda nyata

Data pada Tabel 3 menunjukkan bahwa produktivitas jarak tanam $20 \times 15 \times 40 \mathrm{~cm}$ lebih tinggi $0,614 \mathrm{t} / \mathrm{ha}$ GKG tetapi tidak berbeda nyata dibandingkan produktivitas jarak tanam $20 \times 13 \times 40 \mathrm{~cm}$ dan lebih tinggi 1,592 t/ha GKG dan berbeda nyata dibandingkan produktivitas jarak tanam $20 \times 10 \times 40 \mathrm{~cm}$. Begitu juga produktivitas jarak tanam $20 \times 13 \times$ $40 \mathrm{~cm}$ lebih tinggi $0,978 \mathrm{t} / \mathrm{ha}$ GKG dan berbeda nyata dibandingkan produktivitas jarak tanam $20 \times 10 \times 40 \mathrm{~cm}$. Produktivitas penerapan paket rice transplanter sistem tanam jajar legowo 2:1 jarak tanam $20 \times 15 \times 40 \mathrm{~cm}$ lebih tinggi dan berbeda nyata dibandingkan dengan hasil penerapan paket rice transplanter sistem tanam tegel jarak tanam $30 \times 18 \mathrm{~cm}$ di Desa Jungke Kecamatan Karanganyar Kabupaten Karanganyar pada MT-3 2014 (Kushartanti dan Suhendrata, 2016). Jarak tanam akan mempengaruhi hasil dengan dua cara, yakni penggunaan jarak tanam yang terlalu rapat, tanaman akan mengalami kompetisi dengan tanaman lain didekatnya. Pemakaian jarak tanam yang terlalu lebar mungkin akan mengurangi hasil per satuan luas, karena 
Tota Suhendrata : Pengaruh Jarak Tanam Pada Sistem Tanam...

jumlah tanamannya menjadi berkurang, meskipun ukuran produksi dari masing-masing individu tanaman makin besar. Kerapatan tanam sangat mempengaruhi pertumbuhan, perkembangan dan hasil padi. Jarak tanam bergantung pada kesuburan tanah, musim, dan varietas yang ditanam (Sumarno dan Harnoto, 1983).

\section{Kelayakan finansial}

Aspek efisiensi usahatani merupakan pertimbangan utama dalam pengembangan suatu inovasi teknologi pertanian, karena usahatani yang efisien hanya dapat dihasilkan melalui penerapan teknologi tepat guna sehingga produk yang dihasilkan dapat bersaing di pasar bebas. Untuk mengetahui kelayakan finansial teknologi usahatani menggunakan mesin tanam jarwo transplanter berdasarkan jarak tanam dilihat dengan membandingkan biaya yang dikeluarkan, pendapatan yang diterima, dan keuntungan dari masing-masing jarak tanam.

Tabel 4. Analisis kelayakan finansial teknologi usahatani menggunakan mesin tanam jarwo transplanter berdasarkan jarak tanam di Desa Blimbing Kecamatan Sambirejo Kabupaten Sragen pada MT-3 2014

\begin{tabular}{|c|c|c|c|c|c|}
\hline No. & Uraian & Satuan & Jumlah & $\begin{array}{c}\text { Harga Satuan } \\
\text { (Rp.) }\end{array}$ & $\begin{array}{c}\text { Jumlah } \\
\text { (Rp.) }\end{array}$ \\
\hline \multirow[t]{16}{*}{1} & Biaya & & & & \\
\hline & a. Bibit & Dapog & & 4 & 1.320 .000 \\
\hline & b. Saprodi & & & & \\
\hline & - Urea & $\mathrm{Kg}$ & & 2 & 400 \\
\hline & - Phonska & $\mathrm{Kg}$ & & 2.7 & 810 \\
\hline & - Pestisida & Paket & & 500 & 500 \\
\hline & c. Tenaga kerja & & & & \\
\hline & - Olaha tanah & Borongan & 1 & 900 & 900 \\
\hline & - Pembersihan pematang & Borongan & 1 & 600 & 600 \\
\hline & - Tanam dan sulam & Borongan & 1 & 600 & 600 \\
\hline & - Pemupukan \& penyiangan & HOK & 40 & 50 & 2.000 .000 \\
\hline & - Penyemprotan & HOK & 10 & 50 & 500 \\
\hline & - Panen & Borongan & & 1.750 .000 & 1.750 .000 \\
\hline & d. Pompa air & Paket & & 1.800 .000 & 1.800 .000 \\
\hline & e. Iuran P3A & Paket & & 450 & 450 \\
\hline & Jumlah biaya & & & & 11.630 .000 \\
\hline \multirow[t]{4}{*}{2} & Pendapatan & & & & \\
\hline & a. Jarak tanam: $20 \times 10 \times 40$ & Kg GKP & & 4 & 26.880 .000 \\
\hline & b. Jarak tanam: $20 \times 13 \times 40$ & Kg GKP & & 4 & 30.817 .600 \\
\hline & c. Jarak tanam: $20 \times 15 \times 40$ & Kg GKP & & 4 & 33.456 .000 \\
\hline \multirow[t]{4}{*}{3} & Keuntungan & & & & \\
\hline & a. Jarak tanam: $20 \times 10 \times 40$ & & & & 15.250 .000 \\
\hline & b. Jarak tanam: $20 \times 13 \times 40$ & & & & 19.187.600 \\
\hline & c. Jarak tanam: $20 \times 15 \times 40$ & & & & 21.826 .000 \\
\hline \multirow[t]{4}{*}{4} & $\mathrm{~B} / \mathrm{C}$ & & & & \\
\hline & a. Jarak tanam: $20 \times 10 \times 40$ & & & & 1,3 \\
\hline & b. Jarak tanam: $20 \times 13 \times 40$ & & & & 1,6 \\
\hline & c. Jarak tanam: $20 \times 15 \times 40$ & & & & 1,9 \\
\hline
\end{tabular}


Produktivitas riil GKP berdasarkan jarak tanam merupakan produktivitas hasil ubinan dikoreksi $15 \%$ akibat adanya pematang dan saluran air, sehingga produktivitas riil jarak tanam $20 \times 10$ x $40 \mathrm{~cm}$ menjadi 6,720 t/ha GKP (7.906 $1,186 \mathrm{t} / \mathrm{ha}$ GKP $=6,720 \mathrm{t} / \mathrm{ha}$ GKP), jarak tanam $20 \times 13 \times 40 \mathrm{~cm}=7,704$ t/ha GKP $(9,064-$ $1,360 \mathrm{t} / \mathrm{ha}$ GKP $=7,704 \mathrm{t} / \mathrm{ha}$ GKP), dan jarak tanam $20 \times 15 \times 40 \mathrm{~cm}=8,364 \mathrm{t} / \mathrm{ha}$ GKP $(9,840-1,476 \mathrm{t} / \mathrm{ha}$ GKP $=8,364 \mathrm{t} / \mathrm{ha}$ GKP $)$ (Tabel 4).

Berdasarkan analisis anggaran parsial menujukkan terdapat perbedaan pada hasil gabah dan pendapatan. Ketiga jarak tanam tersebut secara finansial layak dikembangkan karena ketiganya mempunyai $\mathrm{B} / \mathrm{C}$ lebih besar dari 1 tetapi jarak tanam $20 \times 15 \times 40 \mathrm{~cm}$ mempunyai keuntungan atas biaya tunai atau keuntungan tanpa memperhitungkan sewa lahan/opportunity cost lahan (Rp. 21.826.000) dan $\mathrm{B} / \mathrm{C}$ ertinggi $(1,9)$ atau lebih efisien dibandingkan jarak tanam yang lainnya (Tabel 4). Dengan demikian, petani akan mendapatkan keuntungan atau pendapatan tertinggi apabila menerapkan jarak tanam $20 \times 15 \times 40 \mathrm{~cm}$.

Hasil penelitian menunjukkan bahwa perubahan inovasi teknologi sistem tanam tegel jarak tanam $20 \times 20 \mathrm{~cm}$ menjadi sistem tanam jajar legowo $20 \times 10 \times 40 \mathrm{~cm}$ sangat berperan dalam peningkatan produktivitas dan pendapatan petani di Desa Plosorejo Kecamatan Gondang Kabupaten Sragen dan Desa Brujul Kecamatan Jaten Kabupaten Karanganyar (Suhendrata, 2011). Begitu juga perubahan inovasi teknologi varietas dan sistem tanam sangat berperan dalam peningkatan produktivitas dan pendapatan petani di Desa Tanggan, Kecamatan Gesi, Kabupaten Sragen (Suhendrata dan Ngadimin, 2011). Hasil penelitian di Desa Tangkil Kecamatan Sragen Kabupaten Sragen pada bulan Juli - Oktober 2012 menujukkan bahwa produktivitas tanam menggunakan rice transplanter jarak tanam 30 $\mathrm{x} 16 \mathrm{~cm}$ lebih tinggi $0,7 \mathrm{t} / \mathrm{ha}$ dibandingkan jarak tanam $30 \times 18 \mathrm{~cm}$, dan lebih tinggi 1,2 $\mathrm{t} / \mathrm{ha}$ dan $0,5 \mathrm{t} / \mathrm{ha}$ dibandingkan cara tanam manual jarak tanam $20 \times 20 \mathrm{~cm}$ (Suhendrata dan Kushartanti, 2013).

Perubahan cara tanam dari cara manual jarak tanam $22 \times 22 \mathrm{~cm}$ menjadi menggunakan mesin tanam bibit padi (rice transplanter) jarak tanam 30 x $18 \mathrm{~cm}$ berdampak terhadap peningkatan produktivitas dan pendapatan petani dengan margin $\mathrm{B} / \mathrm{C}$ (MBCR) sebesar 6,72 serta peningkatan efisiensi waktu, biaya dan tenaga kerja di Desa Sidoharjo Kecamatan Sidoharjo Kabupaten Sragen pada MT-2 atau Maret - Juli 2014 (Suhendrata, 2015), sedangkan hasil pengkajian di Desa Jungke Kecamatan Karanganyar Kabupaten Karanganyar pada MT-3 2014 menunjukkan bahwa produktivitas dan B/C jarwo transplanter jarak tanam $20 \times 15 \times 40 \mathrm{~cm}$ lebih besar dari transplanter jarak tanam $30 \times 18 \mathrm{~cm}$ dan lebih besar dari cara manual jarak tanam 22 x $22 \mathrm{~cm}$ (Kushartanti dan Suhendrata, 2016).

\section{KESIMPULAN}

1. Jarak tanam berpengaruh nyata terhadap jumlah anakan produktif dan produktivitas padi sawah. Jarak tanam $20 \times 15 \times 40 \mathrm{~cm}$ menunjukkan jumlah anakan produktif dan produktivitas tertinggi dan berbeda nyata dibandingkan dengan jarak tanam $20 \mathrm{x} 10 \mathrm{x}$ $40 \mathrm{~cm}$ dan $20 \times 13 \times 40 \mathrm{~cm}$.

2. Teknologi jajar legowo 2:1 dengan tanam menggunakan mesin tanam jarwo transplanter layak secara finansal dan jarak tanam $20 \quad \mathrm{x} 15 \quad \mathrm{x} \quad 40 \mathrm{~cm}$ paling menguntungkan dibandingkan dengan jarak tanam $20 \times 10 \times 40 \mathrm{~cm}$ dan $20 \times 13 \times 40 \mathrm{~cm}$.

3. Disarankan teknologi ini dapat dikembangkan secara luas oleh petani, sehingga dapat meningkatkan pendapatan petani dan mendongrak produksi padi nasional.

\section{DAFTAR PUSTAKA}

Abdulrachman, S., M. J. Mejaya, N. Agustiani, I. Gunawan, P. Sasmita, dan A. Guswara, 2013. Sistem Tanam Legowo. Badan Penelitian dan Pengembangan Pertanian. Jakarta.

Kushartanti, E dan T. Suhendrata, 2016. Kajian penerapan tanam bibit padi secara mekanik di Kabupaten Karanganyar. Prosiding Seminar Nasional Penyediaan Inovasi dan Strategi Pendampingan untuk Pencapaian Swasembada Pangan. Bergas, 14 Desember 2016. Balai Pengkajian Teknologi Pertanian (inpress). 
Kushartanti, E., dan T. Suhendrata, 2013. Prospek penggunaan mesin tanam pindah bibit padi (rice transplanter) untuk mengatasi kelangkaan tenaga kerja tanam padi di Jawa Tengah. Prosiding Seminar Nasional Akselerasi Pembangunan Pertanian Berkelanjutan Menuju Kemandirian Pangan dan Energi, Solo, 17 April 2013. Fakultas Pertanian UNS. Hal 53-59.

Masdar, 2005. Interaksi jarak tanam dan jumlah bibit per titik tanam pada sistem intensifikasi padi terhadap pertumbuhan vegetatif tanaman. Akta Agrosia Ed. Khusus. (1):92-98.

Muliasari, A. A., 2009. Optimasi jarak tanam dan umur bibit pada padi sawah (Oryza sativa L.). Fakultas Pertanian. Institut Pertanian Bogor.

Permana, S., 1995. Teknologi usahatani mina padi azolla dengan cara tabam jajar legowo. Mimbar saresehan Sistem Usahatani Berbasis Padi di Jawa Tengah. BPTP Ungaran.

Prasetiyo, Y.T. 2005. Budidaya Padi Sawah TOT (Tanpa Olah Tanah). Kanisius. Yogyakarta. 59 hal.

Sembiring, H. 2008. Kebijakan penelitian dan rangkuman hasil penelitian BB Padi dalam mendukung peningkatan produksi beras nasional. Dalam: Prosiding Seminar Apresiasi Hasil Penelitian Padi Menunjang P2BN. Balai Besar Penelitian Tanaman Padi. Hal 39-59.

Suhendrata, T., 2011. Peningkatan produktivitas dan pendapatan petani padi sawah melalui penerapan sistem tanam jajar legowo di Kabupaten Karanganyar dan Sragen. Prosiding Seminar Nasional Implementasi Teknologi Budidaya Tanaman Pangan Menuju Kemandirian Pangan Nasional. Universitas Muhammadiyah Purwokerto.
Suhendrata, T., 2015. Dampak perubahan penerapan teknologi cara tanam bibit padi terhadap produktivitas usahatani padi di Kabupaten Sragen. Prosiding Seminar Nasional Peningkatan Sinergi dan Inovasi Teknologi untuk Kedaulatan Pangan. Yogyakarta, 19 September 2015. Fakultas Pertanian UGM.

Suhendrata, T., dan E. Kushartanti, 2013. Pengaruh penggunaan mesin tanam pindah bibit padi (transplanter) terhadap produktivitas dan pendapatan petani di Desa Tangkil Kecamatan/Kabupaten Sragen. Prosiding Seminar Nasional Akselerasi Pembangunan Pertanian Berkelanjutan Menuju Kemandirian Pangan dan Energi, Solo, 17 April 2013. Fakultas Pertanian UNS. Hal 60-66

Suhendrata, T., dan Ngadimin. 2011. Peran varietas padi dan sistem tanam dalam peningkatan produktivitas dan pendapatan petani pada lahan sawah tadah hujan di Desa Tanggan Kecamatan Gesi Kabupaten Sragen. Prosiding Semnas Mendukung Agro Inovasi Untuk Pemberdayaan Petani Dalam Pengembangan Agribisnis Masyarakat Perdesaan. Kerjasama BBP2TP - Pemda Provinsi Jawa Tengah - Undip.

Sulistiani, R., 2009. Efek jarak tanam terhadap interaksi hara dan mikroba pada pertumbuhan padi sawah (Oryza sativa L.). Sekolah Pascasarjana USU Medan.

Suprihatno, B., A.A. Daradjat, Satoto, Suwarno, E. Lubis, Baehaki S.E., Sudir, S. Dewi Indrasari, I.Putu Wardana, dan Made Jana Mejaya. 2011. Deskripsi varietas Padi. Edisi Revisi. Balai Besar Penelitian Tanaman Padi.

Swastika, D. K. S., 2004. Beberapa teknik analisis dalam penelitian dan pengkajian teknologi pertanian. Jurnal Pengkajian dan Pengembangan Teknologi Pertanian. Vol 7, No.1. BBP2TP Bogor. 